\title{
Calculation of excessive losses in low voltage line caused by computers
}

\author{
${ }^{1}$ Klemen Deželak, ${ }^{1}$ Gorazd Štumberger \\ ${ }^{1}$ University of Maribor, Faculty of Electrical Engineering and Computer Science \\ Smetanova 17, 2000 Maribor, Slovenia \\ phone:+386 2220 7180, fax:+386 2220 7272, e-mail: klemen.dezelak.@uni-mb.si
}

\begin{abstract}
This work estimates excessive losses in low voltage line caused by nonlinear loads. Typical examples of nowadays nonlinear loads are computers, which numbers is especially increased in different types of companies as well as universities. In the case study the excessive losses in low voltage lines caused by the old and new computers are evaluated. The results presented show that the new technologies applied in the new generations of computers increased level of excessive losses in low voltage lines.
\end{abstract}

Key words: low voltage line, excessive losses, nonlinear load, computer, orthogonal current decomposition,

\section{Introduction}

This work evaluates excessive low voltage line losses in the single-phase and three-phase systems caused by computers which represent nonlinear loads. For evaluation of excessive losses orthogonal decomposition of currents [1] is applied. The nonlinear loads in the form of computers can substantially increase excessive losses in the low voltage lines especially in companies with a large number of simultaneously operating computers. These losses depend on load power and RMS values of current [2] - [5]. For higher RMS values of current these losses can increase and can reach more than $10 \%$ of load power. Nowadays, the energy shortage on one hand and the attempts to reduce emissions of greenhouse gases on the other hand, motivate use to address the question excessive losses caused by the computers which are not negligible. In the case study, this work evaluates excessive losses caused by the old and new generations of computers in the single-phase and three-phase low voltage lines.

\section{Orthogonal decomposition of currents}

Mathematical tool orthogonal decomposition of currents can be applied in single-phase systems likewise in threephase systems [1], [6], [7]. This work deals with singlephase (one line current, one phase voltage) and three- phase (three line currents, three phase voltages) systems, where linear and nonlinear loads are considered. In case of single phase system the power factor $P F$ can be calculated, while for three phase system the generalized power factor can be defined $P F^{\prime}$ [6], [7].

\section{Evaluation of excessive low voltage line losses}

In this section the excessive transmission line losses in a low voltage line, actually cable, with length $200 \mathrm{~m}$, are evaluated by orthogonal decomposition of currents. The aforementioned $400 \mathrm{~V}$ low voltage cable supplies a university building with approximately 1100 computers. The evaluation is performed for two different cases. In the first case a single-phase system is applied to supply the computers while in the second case the three-phase supply is applied. Because the number of computers is the same in both cases it is obvious that the line current in the single-phase system is higher than one line current in the three-phase system. Therefore, it is expected higher values of excessive transmission line losses for singlephase system.

Fig. 1 shows single-phase load power applied by singlephase cable $P$ as function of number of "new" computers $N$. This load power increases linear with the increasing number of computers. For $N=1100$ the load power is $P$ $=55573 \mathrm{~W}$. Besides load power, Fig. 1 shows losses in low voltage single-phase cable which cannot be avoid $P_{\text {Rloss }}$ (for $N=1100, P_{\text {Rloss }}=5974 \mathrm{~W}$ ) and excessive losses $P_{\text {Exloss }}$ (for $N=1100, P_{\text {Exloss }}=17162 \mathrm{~W}$ ) which appear due to the nonlinear load. Losses which cannot be avoided $P_{\text {Rloss }}$ are calculated for completely ohmic resistance single-phase load where $P F$ equals 1 . Fig. 2 shows threephase load power $P$ supplied by the three-phase cable given as a function of the number of "new" computers $N$. This load power increases linearly with the increasing number of supplied computers. Besides the load power, Fig. 2 shows losses in low voltage three-phase cable which cannot be avoid $P_{\text {Rloss }}$ and excessive losses $P_{\text {Exloss }}$ caused by the nonlinear three-phase load. The differences excessive low voltage line losses determined for the 
"old" and "new" computers (three-phase load) are shown in Fig. 3.

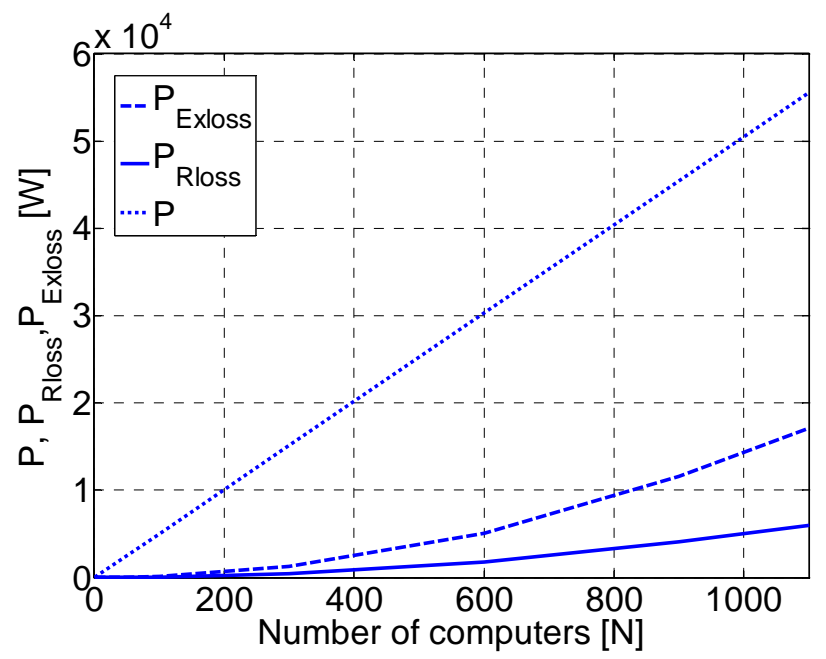

Fig. 1: Load power $P$, losses in low voltage single-phase cable which cannot be avoid $P_{\text {Rloss }}$ and excessive losses $P_{\text {Exloss }}$ which appear due to the nonlinear single-phase load.

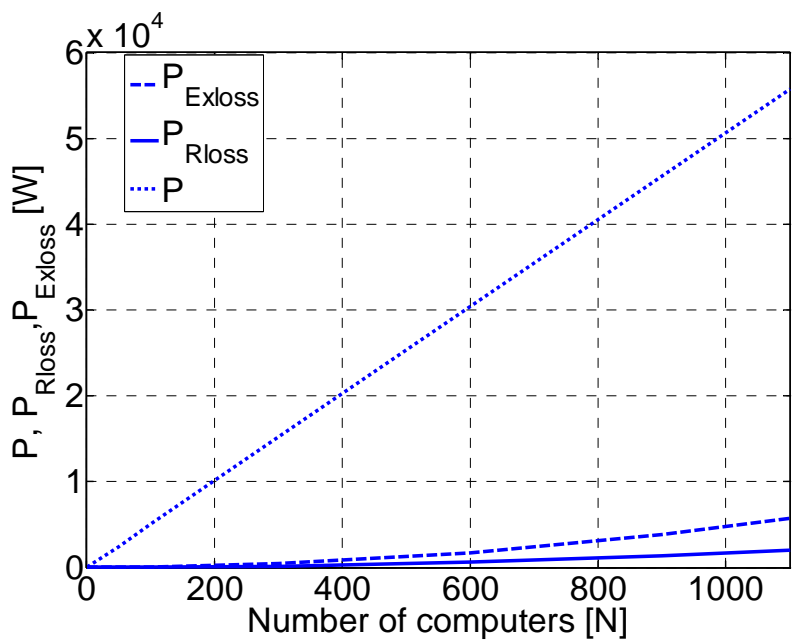

Fig. 2: Load power $P$, losses in low voltage three-phase cable which cannot be avoid $P_{\text {Rloss }}$ and excessive losses $P_{\text {Exloss }}$ caused by the nonlinear three-phase load.

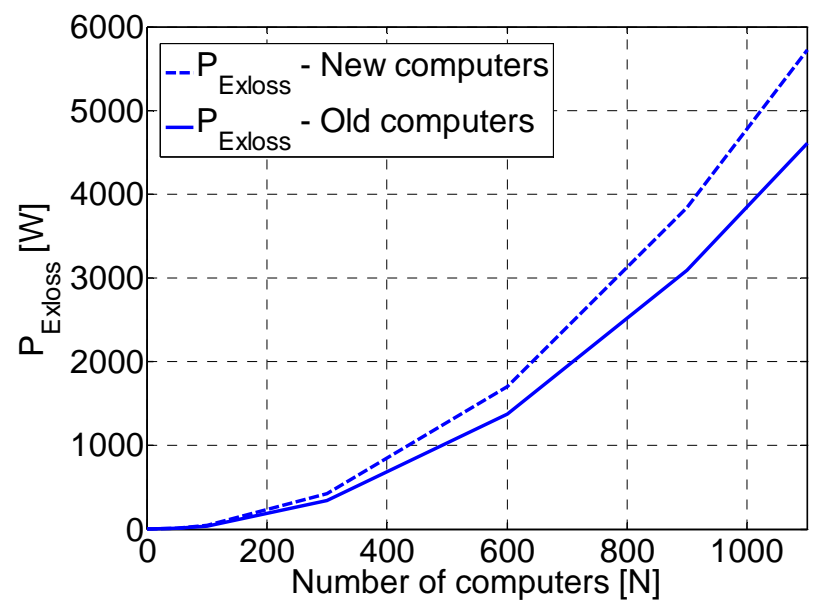

Fig. 3: Excessive losses determined for the "new" and "old" computers in the case of three-phase load.
Based on the comparison of results shown on Figs. 1, 2 and 3 , it is possible to conclude that the values of excessive low voltage line losses are lower for the threephase system. This statement is true only when the threephase and the single-phase low voltage lines supply the same load power.

\section{Conclusion}

This paper evaluates excessive low voltage line losses caused by the nonlinear computer loads. Generally to define these losses in the single-phase and three-phase systems the RMS values of the current and power factor of entire system must be determined. Based on the presented results, we can conclude, that the excessive low voltage line losses can reach even $30 \%$ of the load power. In the case when the same load power is supplied by the three-phase cable these losses reach more than three times lower value than in the case of a single-phase supply cable. Besides this we found out that computers produced by new technologies have worse power factor and higher low voltage line losses than computers produced by old technologies, which is a reason for concern.

\section{References}

[1] L. S. Czarnecki, "Orthogonal Decomposition of the Currents in s 3-Phase Nonlinear Asymmetrical Circuit with a Nonsinusoidal Voltage Source,” IEEE Transactions on Instrumentation and Measurement, vol 37, pp 30-34, March 1988.

[2] L. S. Czarnecki, T. Swietlicki, "Powers in nonsinusoidal networks: Their interpretation, analysis, and measurement," IEEE Transactions on Instrumentation and Measurement, vol 39, pp 340345, April 1990.

[3] R. Sasdelli, G. C. Montanari, "Compesable power for electrical systems in nonsinusoidal conditions ," IEEE Transactions on Instrumentation and Measurement, vol 43, pp 592-598, April 1994.

[4] A. Ferrero, "A new approach to the definition of power components in three-phase systems under nonsinusoidal conditions," IEEE Transactions on Instrumentation and Measurement, vol 40, pp 568577, Jun 1991.

[5] L. S. Czarnecki, S. M. Hsu, G. Chen "Adaptive balancing compensator," IEEE Transactions on Power Delivery, vol. 10, no. 3, pp. 1244-1250, 1996.

[6] G. Štumberger, B. Polajžer, M. Toman, D. Dolinar, "Orthogonal decomposition of currents, power definitions and energy transmission in three-phase systems treated in the time domain", Proceedings of the International conference on renewable energies and power quality (ICREPQ' 06), Palma de Mallorca, Spain, April 2006.

[7] K. Deželak, G. Štumberger, "Evaluation of excessive transmission line losses caused by unbalanced and nonlinear three-phase loads", Proceedings of the International conference on renewable energies and power quality (ICREPQ' 08), Santander, Spain, March 2008. 